\title{
Contexto nacional e as exigências para a pesquisa em educação
}

Conceição Paludo'

\section{RESUMO}

Neste artigo, tendo como apoio estudos e pesquisas que venho realizando, assim como revisão bibliográfica, pretendo contribuir para a análise da atualidade brasileira e pontuar alguns desafios para a pesquisa em educação. $\mathrm{O}$ que se realiza a partir da perspectiva teórico-metodológica do materialismo histórico-dialético. Conclui-se que alguns dos desafios centrais para o pesquisador, notadamente na grande área das ciências humanas, na qual se inclui a educação, são: revisão do referencial teórico e metodológico; a necessidade de debruçar-se sobre a teoria, revendo conceitos e categorias fundamentais para a análise da realidade; assumir a perspectiva da defesa radical da sociedade; articular-se em redes; aproximar-se dos extratos populares; denunciar retrocessos e anunciar possibilidades. Enfim, assumir a dimensão política do pensar e fazer pesquisas.

PALAVRAS-CHAVE

contexto; Brasil; pesquisa; desafios.

'Universidade Federal do Rio Grande do Sul, Porto Alegre, RS, Brasil. 


\title{
NATIONAL CONTEXT AND REQUIREMENTS FOR EDUCATION RESEARCH
}

\begin{abstract}
In this article, supported by researches, studies and literature review, it is intended to contribute in analyzing Brazilian reality and emphasizing the challenges in education research, which is achieved by a theoretical-methodological perspective of historical dialectical materialism. We concluded that the main challenges for researchers, in the wide area of Humanities in which Education is included, are: review of theoretical and methodological frame of reference; necessity of extensive readings and reviewing concepts to analyze reality; commitment to radical defense of society; movement between networks; approximation to lower classes; exposure of regressions and announcement of possibilities. Finally, to assume the political dimension of thinking and researching.
\end{abstract}

KEYWORDS

context; Brazil; research; challenges.

\section{CONTEXTO NACIONAL Y LAS EXIGENCIAS PARA LA INVESTIGACIÓN EN EDUCACIÓN}

\section{RESUMEN}

En este artículo, teniendo como apoyo estudios e investigaciones que vengo realizando, así como revisión bibliográfica, pretendo contribuir para el análisis de la actualidad brasileña y puntuar algunos desafíos para la investigación en Educación. Lo que se realiza a partir de la perspectiva teórica metodológica del materialismo histórico dialéctico. Se concluye que algunos de los desafíos centrales para el investigador, notadamente en la gran área de las ciencias humanas, en la que se incluye la Educación, son: revisión del referencial teórico y metodológico; la necesidad de inclinarse sobre la teoría, revisando conceptos y categorías fundamentales para el análisis de la realidad; asumir la perspectiva de la defensa radical de la sociedad; articularse en redes; acercarse a los extractos populares; denunciar retrocesos y anunciar posibilidades. En fin, asumir la dimensión política del pensar y hacer investigaciones.

PALABRAS CLAVE

contexto; Brasil; investigación; desafíos. 


\section{INTRODUÇÃO}

Enfrentamos, desde o final do século passado, uma situação de crise, nomeada por muitos como crise civilizatória. Para Gramsci (1978), as crises representam a luta dolorosa que se trava entre o velho e o novo. $\mathrm{Na}$ atualidade, o novo que desponta remete para o velho, para o retorno aos primórdios da constituição do capitalismo: terra sem lei, ou melhor, na qual "a lei do capital" imperava soberana. Esse novo/velho, pode-se dizer, remontando a Marx, é "síntese de múltiplas determinações" e exige, como alerta Freire $(1995$, p. 23), "não renunciar à luta pelo exercício de nossa capacidade e de nosso direito de decidir e de romper, sem o qual não reinventamos o mundo".

Para a escrita deste artigo, além da revisão bibliográfica, retomamos estudos e pesquisas realizados ao longo de doze anos. Além disso, partimos de alguns lineamentos teórico-metodológicos, dentre os quais destacamos os seguintes:

- sob o capitalismo - sociedade marcada pela divisão social do trabalho por classes sociais antagônicas, pela dicotomização do trabalho e do ócio e pela desigualdade no usufruto do patrimônio científico e cultural - para ter avanços, na reinvenção do mundo, proposta por Freire, o campo do trabalho luta e deverá seguir lutando, tendo como parâmetro os direitos do gênero humano, para a obtenção do mínimo;

- o povo segue sendo sujeito central do movimento gerador de mudanças para reinventar o mundo, pelo simples fato de ser o que mais necessita de avanços, por menores que sejam, e porque, transformando-se em força política, barra retrocessos, institui direitos, luta para implementá-los;

- intelectuais e a classe trabalhadora, para que se adentrem na luta pela instituição de direitos ou para resistir à sua desconstituição, necessitam estar em comunicação e vinculados organicamente;

- os intelectuais não são neutros e o ofício da pesquisa também não o é;

- no aspecto teórico-metodológico, é importante retomar a análise da realidade, tendo como eixos a totalidade, a historicidade, as mediações e as contradições, o que também se nomeia de complexidade;

- a educação, quer seja escolar ou não escolar, conecta-se diretamente com a economia e com a política, além da cultura, constituindo importante instrumento de reprodução sociocultural passiva;

- a ingenuidade levou a acreditar que, no Brasil (e no mundo), seria possível a universalização do Estado de bem-estar social, porém o que se presencia, mundialmente, é um retrocesso, acompanhado de consequências que se manifestam no âmbito da sociabilidade humana e que impactam, como o galope do retorno da fome, literalmente, o nazifascismo e a xenofobia de toda a ordem, fragmentação e desconstituição de parâmetros mínimos no âmbito dos valores.

Com essa compreensão mais ampla, o presente artigo pretende contribuir para o entendimento do contexto brasileiro atual e delinear alguns desafios para a pesquisa em educação. 


\section{A DIALÉTICA MATERIALISTA E OS PROCESSOS DE PESQUISA: ALGUNS LINEAMENTOS TEÓRICOS E METODOLÓGICOS PARA A ANÁLISE DO CONTEXTO}

Para a leitura do contexto brasileiro, parte-se do entendimento de que a prática da pesquisa exige, do pesquisador, a clareza teórica e o rigor epistemológico, que estão sempre relacionados ao seu entendimento ontológico, à sua visão mais ampla do desenvolvimento social e ao que propõe como finalidade do conhecimento que produz.

De acordo com Triviños (1987), as três correntes do pensamento contemporâneo que guiam a pesquisa em ciências sociais são o positivismo, a fenomenologia e o marxismo. Para o autor, o positivismo predominou, de forma incontestável, até a década de 1970, quando perdeu sustentação devido às críticas sofridas pelas suas práticas de investigação e pelas consequências do conhecimento produzido.

A perspectiva adotada na análise abaixo realizada, como se anunciou na introdução, é o materialismo histórico-dialético. Essa abordagem teórico-metodológica, como se sabe, foi formulada por Marx e Engels, ainda no século XIX, e corresponde ao que se pode denominar um fazer científico engajado com processos de emancipação humana, cujo horizonte mais amplo é a transformação do modo de produção capitalista, uma vez que, nele, não há possibilidade de se chegar a uma sociedade emancipada. Na obra Para a questão judaica, Marx (2009) define a emancipação humana como emancipação social, entendimento que vai além da emancipação religiosa ou política, ainda que reconheça a importância dessas.

De acordo com o que sugere a obra $A$ ideologia alemã (2009), escrita entre 1845 e 1846, o materialismo histórico é, de acordo com Marx e Engels, o "fio condutor" de todos os estudos subsequentes. Os conceitos básicos do materialismo histórico constituem uma teoria científica da história. Eles revolucionaram a maneira de se interpretar a ação dos homens na história, abrindo ao conhecimento uma nova ciência e aos homens uma nova visão filosófica do mundo: o materialismo dialético. Pode-se afirmar, corroborando Frigotto (2000), que a compreensão materialista, histórica e dialética é, ao mesmo tempo, concepção de realidade, método e práxis transformadora.

Para os autores, na sociedade capitalista ou no "modo de produção capitalista", as relações sociais de produção são de exploração da força de trabalho, com o objetivo de produção de mais-valia. O que sustenta isso, basicamente, é:

- a divisão social do trabalho - divisão entre proprietários e não proprietários dos meios de produção e entre trabalho intelectual e manual;

- a alienação, que indica a carência de relação entre a base material da produção da vida em sociedade e a consciência que dela se tem.

O trabalhador não produz para si, mas para o capital. Por isso, não é mais suficiente que ele apenas produza. Ele tem de produzir mais-valia. Só é produtivo o trabalhador que produz mais-valia para o capitalista, servindo assim à auto expansão do capital [...]. O conceito de trabalho produtivo não compreende apenas uma relação entre atividade e efeito útil, entre trabalhador e produto do 
trabalho, mas também uma relação de produção especificamente social, de origem histórica, que faz do trabalhador o instrumento direto de criar mais-valia. Ser produtivo não é nenhuma felicidade, mas azar. (Marx, 2002, p. 578)

Igualmente, são essas relações de exploração da força de trabalho que se subordinam à lógica da acumulação das riquezas, que instituem as duas classes sociais fundamentais da sociedade: a burguesia e os trabalhadores. Essas classes possuem interesses antagônicos, daí Marx e Engels afirmarem que a luta entre as classes é um elemento fundamental e que condiciona o conjunto das relações. Portanto, conflito e consenso, repressão e hegemonia, alienação e criticidade, aparência e essência dos fenômenos sociais, encobrimento e desvelamento da realidade, ideologia e ciência, adaptação à ordem e resistência/luta, são exemplos de pares dialéticos que expressam as contradições presentes nas relações sociais, ainda que se manifestem, de modo diferenciado, em dado momento do processo histórico (Marx e Engels, 2008).

Com esses pressupostos, Marx e Engels instituíram o trabalho, em seu sentido ontológico e histórico, como sendo de capital importância na compreensão do desenvolvimento dos seres humanos, das relações que estabelecem entre si e com a natureza. Além disso, os autores atribuíram ao processo de desenvolvimento um caráter material, ao analisarem que os seres humanos se organizam na sociedade para a produção e a reprodução da vida, e um caráter histórico, ao explicitarem como eles vêm se organizando através da história.

Já naquele momento, século XIX, também analisavam que a ciência, cada vez mais especializada, apresentava-se como algo "autônomo", independente da atividade humana e não subordinada aos interesses do capitalismo. Igualmente, para a análise da educação escolar, por exemplo, realizavam uma distinção importante entre a cultura da classe trabalhadora de nível cultural e indicaram claramente que, sob o capitalismo, a cultura geral é negada às massas populares. Nesse mesmo sentido, os autores apontavam claramente a divisão entre a escola para as elites e a escola para as classes trabalhadoras, o que aprofunda a divisão social do trabalho entre os que pensam e os que executam e possibilita, igualmente, o aprofundamento dos processos de alienação e reprodução social. ${ }^{1}$

Ao caracterizar o método de pesquisa que foi sendo formulado no próprio processo de produção do conhecimento, Marx e Engels remetem com frequência a Hegel, como o filósofo que formulou os princípios da dialética, bem como a Feuerbach, que resgatou a concepção materialista. A primeira foi criticada pelos autores como sendo idealista e a segunda como sendo materialista "contemplativa".

1 As obras nas quais Marx analisa a educação e o papel do conhecimento, de acordo com Manacorda (1991), são as seguintes: a) 1847-1848, quando sobressai o texto do $M a-$ nifesto do Partido Comunista; b) 1866-1867, momento em que foi redigido o texto das Instruções aos delegados do Conselho Geral Provisório do I Congresso da Associação Internacional dos Trabalhadores, entrelaçado e sobreposto às passagens de O Capital referidas à educação. Nessa época, Marx estava concentrado na redação de O Capital, motivo que o levou à decisão de não comparecer ao congresso que se reuniu no início de setembro de 1866; c) 1875 , ano da redação das Notas à margem do Programa do Partido Operário Alemão, conhecidas como Critica ao Programa de Gotha. 
Sobre Hegel, Marx assevera:

Meu método dialético, por seu fundamento, difere do método hegeliano, sendo a ele inteiramente oposto. Para Hegel, o processo do pensamento - que ele transforma em sujeito autônomo sob o nome de ideia - é o criador do real, e o real é apenas a sua manifestação externa. Para mim, ao contrário, o ideal não é mais do que o material transposto para a cabeça do ser humano e por ele interpretado. (Marx, 2002, p. 28)

E sobre Feuerbach, assim se pronunciam, na obra $A$ Ideologia Alemã, nas conhecidas teses sobre o autor.

(VI) Feuerbach dissolve a essência religiosa na essência bumana. Mas a essência humana não é uma abstração intrínseca ao indivíduo isolado. Em sua realidade, ele é o conjunto das relações sociais. Feuerbach, que não penetra na crítica dessa essência real, é forçado, por isso: 1 - a fazer abstração do curso da histórica, fixando o sentimento religioso para si mesmo, e a pressupor um indivíduo humano abstrato - isolado; 2 - por isso, nele a essência humana pode ser concebida como "gênero", como generalidade interna, muda, que une muitos indivíduos de modo meramente natural (Marx e Engels, 2009, p. 125, grifos do original) (VII) Feuerbach não vê, por isso, que o "sentimento religioso" é, ele mesmo, um produto social, e que o indivíduo abstrato que ele analisa pertence, na realidade, a uma determinada forma de sociedade. (Marx e Engels, 2009, p. 125, grifos do original)

Tais críticas se fundamentam no entendimento de Marx e Engels sobre o que é a realidade social, em suas diferentes dimensões, como ela é produzida e como se chega a compreendê-la, a interpretá-la. Assim, para os formuladores do materialismo histórico-dialético, a matriz da realidade não são as ideias, traduzidas nas mais diferentes formas, mas sim as relações materiais concretas que os seres humanos estabelecem entre si e com a natureza que vão constituindo a história humana e as ideias que aí se produzem. Desse modo, é absolutamente necessário buscar as conexões das ideias produzidas com a realidade objetiva. Esse é um princípio da dialética que, aplicado ao social, afirma a historicidade de todas as instituições, estruturas, leis, mentalidades e formas de vida social. Da mesma forma, as visões sociais de mundo se constituem em produtos sociais e podem ser analisadas em seu desenvolvimento histórico, nas transformações por que vão passando.

No plano epistemológico, dessa maneira, para os autores, a realidade existe independentemente do pensamento. O pensamento é parte da realidade e se constitui na relação com a realidade. A dialética está na realidade: síntese de múltiplas, ricas e complexas determinações e condicionamentos. A realidade está sempre em transformação e não existe nada eterno, absoluto. Nada é estabelecido de uma vez por todas. Tudo o que acontece na vida humana e social está sujeito ao fluxo da história, que é feita pelos próprios seres humanos. Sendo assim, a validade do conhecimento não pode ser nem a autoridade (cientista/chefe/bíblia), nem a evidência (o que se impõe pela força da qualidade persuasiva), nem a utilidade (o verdadeiro 
é o útil), porque, para os autores, a prática social, além de ser o critério do conhecimento, está na sua base e no seu propósito final. Na base porque foi a partir da práxis social que o ser humano produziu e produz sua existência e constituiu tanto a capacidade de conhecer quanto os conhecimentos. No propósito final porque a finalidade do conhecimento é a transformação das práxis social. Teoria e prática estão interligadas e designam os aspectos espiritual e material da atividade humana, que é objetiva e sócio-histórica. E a partir desse entendimento que as categorias centrais do método do fazer científico são: a apreensão da materialidade e do movimento, ou seja, da historicidade; a visão de totalidade, que indica a necessidade de estabelecimento das relações entre o fenômeno estudado e a totalidade social; o entendimento das contradições, que explicitam os conflitos e obstáculos que se colocam para os avanços; e as mediações, que indicam as intervenções possíveis em um dado momento histórico.

Portanto, o papel da ciência é apoderar-se da matéria em seus pormenores, analisar suas diferentes formas de desenvolvimento e perquirir a conexão íntima que há entre elas, para, então, escrever o movimento real. Marx e Engels explicitam que a reflexão sobre as formas de vida social - e, portanto, a sua análise científi$\mathrm{ca}$ - segue uma via contrária ao movimento real. Ela começa a posteriori, com dados já estabelecidos, com os resultados do desenvolvimento (Marx, 2002). Dessa forma, os autores distinguem o método de investigação - que consiste no esforço de apropriação detalhada da realidade, ou seja, no esforço rigoroso do pensamento em compreender/interpretar a realidade, colocando em evidência as relações, visando a transformá-las (momento regressivo) — do método de exposição, que se refere à apresentação, à síntese do objeto ou ao fenômeno estudado (momento progressivo) (Marx, 2002).

Frigotto (2000) apresenta uma síntese desse caminho proposto pelo método nos seguintes termos:

- passar da aparência para a essência (do abstrato falso para o concreto verdadeiro), e que se regresse à aparência compreendida como forma fenomenal da essência (unidade da essência e da aparência);

- dirigir-se à própria coisa, fatos empíricos que nos são dados pela realidade;

- superar as impressões primeiras, as representações fenomênicas e ascender ao concreto: como eles estão sendo feitos?

- o ponto de chegada é o concreto pensado, que demanda um trabalho de organização e exposição dos fatos. Esse é um processo de abstração que supõe a relação permanente entre: parte e todo; essência e aparência; sujeito e objeto; encobrimento e desvelamento da realidade.

Dessa maneira, para o mesmo autor, não é possível tomar o método como um conjunto de estratégias, técnicas e instrumentos. $\mathrm{O}$ referencial teórico não pode ser compreendido como uma camisa de força porque as categorias do método podem se tornar abstratas e especulativas, vazias de historicidade. Também não é possível contrapor quantidade e qualidade, e há de se ter o cuidado de não confundir leitura empiricista com a realidade empírica, da qual devem emergir os conhecimentos. 
Por isso mesmo, "a dialética nunca pode ser registrada, nem aprendida de cor. Ela só pode ser assimilada pelo aprendizado crítico dentro da própria prática"(Thompson, 1981, p. 129).

Com base nos escritos de Marx e Engels, nas primeiras décadas do século XX, Gramsci (1982), fundamentando-se no materialismo histórico-dialético e interpretando o estágio de desenvolvimento da sociedade capitalista do seu tempo, faz uma análise sobre os intelectuais que contribui para a nossa reflexão. Afirmando que todos os homens são intelectuais, o autor assevera que nem todos os homens desempenham na sociedade a função de intelectuais (Gramsci, 1982). Essa afirmativa é decorrência do modo como o autor trata a questão dos intelectuais na sociedade de classes e no conjunto das relações sociais. Para o autor, o papel social dos intelectuais é definido pela sua organicidade aos projetos de classe, visando à manutenção da hegemonia ou à contribuição para o exercício da contra-hegemonia, no interior das configurações que assume o Estado ampliado, ou integral, em cada época do processo histórico. Quer dizer, a função do intelectual está vinculada à sua organicidade a classes fundamentais e extratos/frações de classe no seu interior. Ainda que não se possa dizer que todos os intelectuais que, de alguma forma, contribuem para a disseminação de visões sociais de mundo sejam pesquisadores, produtores de conhecimento, analisamos que, a partir da perspectiva aqui adotada, pode-se dizer que todos os pesquisadores são intelectuais e, como tais, vinculam-se a projetos societários em disputa na sociedade. $\mathrm{O}$ conhecimento produzido por meio das investigações realizadas, dessa maneira, coloca-se na perspectiva de construção de processos emancipadores ou reificadores da sociedade que aí está.

\section{PARA ALÉM DO BRASIL: A CRISE É GLOBAL E CIVILIZATÓRIA}

Marx, no século XIX (1988), alertava sobre o processo de acumulação, concentração e centralização de capitais; assim como sobre as crises cíclicas de acumulação. Trotski (1905) evidenciou, no início do século XX, a lei do desenvolvimento desigual e combinado, entre nações e no interior de cada país. Fernandes (2009) estudou o desenvolvimento latino-americano e brasileiro, e um dos elementos que destacou foi o redirecionamento do padrão de acumulação de capital, a cada crise, sem, no entanto, existir a alteração dos pressupostos do modo de produção capitalista, conforme analisou Chauí (2007).

Para a autora, as transformações atuais colocam em questão a compreensão do Estado no modo de produção capitalista, evidenciando a necessidade de retomar a análise central de "O Capital [...] como crítica materialista da economia política burguesa, que separa, para poder melhor ocultar as relações de classe e a exploração na qual se baseia" (Chauí, 1982, p. 118). Em outra obra, assevera que

O devir é a sucessão temporal dos modos de produção ou o movimento pelo qual os pressupostos de um novo modo de produção são condições sociais que foram postas pelo modo de produção anterior e serão postas pelo novo modo de produção. O desenvolvimento é o movimento interno de um modo de produção para repor o seu pressuposto [...]; refere-se, portanto, a uma forma par- 
ticular [...] de um modo de produção, cujo desenvolvimento é dito completo quando o sistema tem a capacidade para repor internamente e por inteiro o seu pressuposto. (Chauí, 2007, p. 143)

A autora complementa, dizendo que "[...] a forma completa termina quando, ao repor completamente os seus pressupostos, põe uma contradição interna nova que ela não pode resolver sem se destruir" (Chauí, 2007, p. 114). Isso revela a finitude da forma histórica e a infinitude do devir.

A organização e a reorganização do Estado moderno acompanham esse movimento e, embora esse processo não represente simplesmente o Estado como "comitê executivo da burguesia", a "existência da forma de política estatal é necessária à reprodução capitalista” (Mascaro, 2013, p. 61), como facilitadora da manutenção das relações sociais de exploração da força de trabalho e, consequentemente, da mais-valia. $\mathrm{O}$ autor diz que essa relação contraditória entre as classes não fica evidente porque "abre-se a separação entre o domínio econômico e o domínio político" (Mascaro, 2013, p. 17). Nesse mesmo sentido, a organização e o papel do Estado capitalista ficam explicitados com os estudos de Poulantzas (1985). O autor compreende o Estado como condensador das relações de classe social, em desenvolvimento, em um dado momento histórico. O que nos direciona a um patamar mais elevado e complexo de entendimento da dinâmica social.

Foi assim que, globalmente, a partir dos anos 1970, viu-se o processo de acumulação do capital ser redirecionado. Do século XIV ao início do século XX, houve a predominância do capital no comando do conjunto das relações sociais. Após a Segunda Guerra Mundial - em um contexto de Guerra Fria, sindicatos fortes, final da guerra e suas consequências, bem como exploração e espoliação do chamado terceiro mundo - o direcionamento do desenvolvimento, ainda entendido como crescimento econômico e avanço tecnológico, deu lugar ao que se conhece como Estado de bem-estar social, que, como se sabe, consiste em uma crença de que o capitalismo possa ser humanizado.

A luta dos trabalhadores por melhores condições de vida e por uma situação mais digna de trabalho construiu a experiência de determinado padrão de proteção social, no período de 1945 a 1975, nos países do centro do capitalismo. Para tanto, foi decisiva a intervenção do Estado acoplada com as políticas de cunho keynesiano/fordista, destacando-se as modificações redistributivas no orçamento público: pelo lado do financiamento, a implantação de sistemas tributários mais justos tendo como base a cobrança de impostos diretos e progressivos; pelo lado dos gastos, destaca-se, entre as políticas sociais, a edificação da seguridade social, articulando as políticas de seguros sociais, saúde e auxílios assistenciais. (Salvador, 2010, p. 607)

$\mathrm{Na}$ atualidade, o Estado de bem-estar social está sendo desconstituído. A crise do capital dos anos 1970 constituiu-se na condição de implementação do neoliberalismo, tendo como articuladores, ao longo do processo, uma série de organismos multilaterais, especialmente a partir do Consenso de Washington. 
A teoria do "neoliberalismo" nasceu logo depois da Segunda Guerra Mundial, na região da Europa e da América do Norte. Foi uma reação teórica e política veemente contra o Estado intervencionista e de bem-estar. Seu texto de origem é O caminho da servidão, de Friedrich Hayek, escrito já em 1944. Trata-se de um ataque apaixonado contra qualquer limitação dos mecanismos de mercado por parte do Estado, denunciadas como uma ameaça letal à liberdade, não somente econômica, mas também política. (Anderson, 1995, p. 9)

O neoliberalismo equivale ao domínio da economia sobre o social e foi intensificado no contexto da cumulação flexível, sendo também identificado como "liberalizante-privatizante, onde o foco principal é a manutenção da acumulação [...], onde o público dá lugar ao privado" (Soares, 1998, p. 21).

O início desse período de crise e transição, do padrão de acumulação do capital, que levou a mudanças profundas, tanto no campo das relações de trabalho quanto na sociabilidade, foi analisado por Antunes (2011) como crise estrutural ou acumulação por espoliação.

Ao contrário, portanto, dos ciclos de expansão que conformaram o capitalismo ao longo de sua história, alternando períodos de expansão e crise, encontramo-nos, desde fins dos anos 60 e início dos 70, mergulhados no que István Mészáros denomina como depressed continuum que exibe as características de crise estrutural. (Antunes, 2011, p. 12)

É nesse cenário que o debate em torno da democracia ganha enorme destaque. Para Chauí (2007), a democracia como expressão de um regime político também deve ser analisada em sua relação com a estrutura da sociedade. Assim, embora ressalve a importância, em termos históricos, do regime democrático liberal, evidencia seus limites. Coutinho (1997, p. 145) "define democracia como a presença efetiva das condições sociais e institucionais que possibilitam ao conjunto dos cidadãos a participação ativa na formação do governo e, em consequência, no controle da vida social".

De acordo com os estudos que estamos realizando, é a partir da crise estrutural do capital e do redirecionamento do seu padrão de acumulação e, consequentemente, dos processos produtivos, via chamada reestruturação produtiva, embora não exclusivamente, que se pode compreender as guerras, as transformações no papel do Estado, a desconstituição das políticas públicas como direito, a sociabilidade que se torna mais e mais competitiva e o papel que se quer que a educação cumpra. Ou melhor, para continuar desempenhando o papel que historicamente desempenhou, a educação está em processo de adaptação às novas necessidades de manutenção e revigoramento do pressuposto do modo de produção capitalista, que acima abordamos. Com esse entendimento, não há possibilidade de uma análise séria da realidade educacional sem o pressuposto do vínculo com o modo de produção vigente e com as relações impostas pelo capital ao Estado, que também sustentam as ações no campo da política educacional, dada a sua importância na internalização de valores que promovam o aquietamento das classes populares e a adesão necessária. 
Na perspectiva de análise acima colocada, a história do capitalismo é a história da recolocação dos seus pressupostos. "[...] O capitalismo, desde o início, teve que, seguida e permanentemente, revolucionar-se sem cessar e expropriar os trabalhadores, tanto em relação aos instrumentos de produção quanto ao conhecimento e à identidade; expropriá-los na sua própria condição de existência enquanto classe" (Dias, s.d., p. 46).

As análises do momento atual são as de que o ideário neoliberal vem sofrendo uma espécie de aprofundamento. De início, a opção parecia ser a de uma mediação, também denominada de "terceira via" ou "terceiro setor", pela implementação das políticas distributivas de cunho compensatório, que garantiam não só votos como também a governabilidade na continuidade do modo de produção capitalista, obtida pelo consenso (Paludo e Vitoria, 2014).

No entanto, na análise de Petras (2010, s.p.),

[...] a terceira via já chegou ao seu limite, especialmente na Europa e particularmente onde tudo começou, na Inglaterra. [...]. A terceira via não era realmente uma terceira via. Era uma forma de liberdade de mercado capitalista com aumento nos gastos sociais, sem a realização de mudanças estruturais. Então, quando a crise financeira veio, teve um impacto muito grande: incorporada à realização das políticas, estavam as ideias de que o sistema financeiro deveria ser poupado acima de tudo.

Pode-se dizer que gastos sociais e liberdade de mercado constituem uma contradição, no enfrentamento à crise estrutural do capital. A superação da crise do capital direciona a um retrocesso sem precedentes na história do capitalismo, a uma espécie de retorno ao início do mesmo.

Além disso, constata-se escassez de resistência, algo que seja efetivamente significativo, diante da avalanche de "destruição criativa". Para Harvey, a questão central é que "[...] não há movimento anticapitalista suficientemente unificado" (Harvey, 2011, p. 184), o que gerou a "falta de uma visão alternativa que impede a formação de um movimento de oposição, e a ausência de tal movimento opõe-se à articulação de uma alternativa" (Harvey, 2011, p. 184). O mesmo autor aponta que a primeira e mais importante ação, para um salto qualitativo, seria assumir o controle da produção e a distribuição de excedentes.

Sob a hegemonia do capital, com forte ideia assinalada pelo "fim da história”, pelo avanço tecnológico sem precedentes, pela intensificação da globalização, pelo fim do chamado socialismo real, pela desorientação da esquerda, pela adesão ao pós-moderno, entre tantos outros aspectos, o que se observa é o acirramento da luta de classes, o ressurgimento de práticas nazistas e fascistas, que eclodem nas mais diversas xenofobias, o aumento da fome no mundo, do desemprego, da violência, da fragmentação do tecido social e da perda de parâmetros éticos e morais de sociabilidade.

Economicamente, o neoliberalismo fracassou, não conseguindo nenhuma revitalização básica do capitalismo avançado. Socialmente, ao contrário, o neoliberalismo conseguiu muitos dos seus objetivos, criando sociedades marcadamente 
mais desiguais, embora não tão desestatizadas como queria. Política e ideologicamente, todavia, o neoliberalismo alcançou êxito num grau com o qual seus fundadores provavelmente jamais sonham, disseminando a simples ideia de que não há alternativas para os seus princípios, que todos, seja confessando ou negando, têm de adaptar-se a suas normas. (Anderson, 1995, p. 20)

O contexto específico brasileiro se insere nesse espectro, nessa dinâmica global, que indica um desfecho nada auspicioso, se pensarmos como gênero humano.

\section{O BRASIL NISSO TUDO}

O Brasil contemporâneo se define assim: o passado colonial que se balanceia e se encerra com o século XVIII, mais as transformações que se sucedem no decorrer do centênio anterior a este e no atual. (Prado Júnior, 1992, p. 10)

A história do Brasil, a par e a mercê de suas riquezas e belezas naturais, é uma triste história para os mais empobrecidos e para o que se convencionou chamar de minorias, notadamente no que diz respeito à produção e à reprodução da vida material e, consequentemente, da espiritual.

Conectado ao capitalismo desde o início, no Brasil, as relações de dependência das metrópoles hegemônicas sempre estiveram presentes: Portugal, Inglaterra e Estados Unidos. Sob o modelo agrário exportador, que atravessou o império e foi efetivamente redirecionado na Revolução de 1930, ainda que não sem resistências e lutas, houve a dizimação dos indígenas, povos originários, e a escravidão dos negros. O que ocorreu, segundo Ribeiro (1997), foi um processo civilizatório que se processou por "atualização ou incorporação histórica", o que supõe a perda da autonomia étnica dos núcleos engajados, sua transfiguração e dominação.

Referindo-se à independência e ao império, Ianni (1996, p. 20) assim sintetiza o processo vivido:

A persistência do escravismo e os artifícios do manto monárquico configuravam um poder estatal com as características de uma administração distante, alheia aos interesses populares. A legitimidade alcançada pelos construtores do Estado nacional, quando se resolveram pelo regime monárquico, teve sempre o peso de uma legitimidade imposta não só pelo alto, mas estrangeira, no sentido de indiferente aos movimentos mais gerais da sociedade.

César Benjamim (1998, p. 25) analisa esse período como um trânsito, cujas características centrais seriam:

- do encontro de grupos étnicos à formação de um povo dotado de identidade linguística e identidade cultural;

- dos governos coloniais a um Estado nacional capaz de cumprir funções estruturantes cada vez mais complexas;

- da prevalência do mercado externo à do mercado interno como fonte de estímulo aos setores mais dinâmicos da economia; 
- da máxima apartação social (o escravismo) à cidadania e às aspirações de generalização de uma cidadania real;

- da fragmentação à unificação da base geográfica;

- do modelo primário exportador à predominância da indústria;

- da população dispersa no meio rural a uma sociedade urbanizada.(Benjamim, 1998, p. 25)

A República trouxe um novo regime e, com ele, o modelo de substituição de importações.

[A República] consolidou-se sobre a vitória da ideologia liberal pré-democrática, darwinista, reforçadora do poder oligárquico. As propostas alternativas de organização do poder, o republicanismo radical, a do socialismo e mesmo a do positivismo, derrotadas, foram postas de lado. (Carvalho, 1997, p. 162-163)

Com a República, a inversão que ocorre é que a hierarquia naturalizada é desfeita. $\mathrm{O}$ povo, majoritariamente escravos e indígenas, antes concebidos como particularidade disfuncional e necessária para a reprodução da riqueza, passam a constituir o universal, no qual todos, independentemente de raça e cor, idade, orientação sexual, gênero, religião ou posses, são considerados cidadãos perante a lei e todos podem, teoricamente, ascender socialmente (Chauí, 1986). Nesse contexto, a ilustração, ideário cultural e político, tem o seu encontro definitivo com o capitalismo. E é nesse movimento que se forjam o novo pensamento e as práticas políticas hegemônicas. Analisando o que ocorre, Salazar (1990) assevera que a integração de todo o povo é formal, visto que a segregação real continua, embora a forma seja diferenciada. É importante lembrar que a República também consolida o latifúndio, hoje transmutado em agronegócio. A Lei das Terras, de 1850, foi a primeira iniciativa no sentido de regulamentar a propriedade privada da terra no Brasil. E ainda na atualidade, indígenas, quilombolas e sem-terra lutam pela questão agrária.

A par dos novos ideários, o que ocorre é a ascensão da burguesia aliada às oligarquias agrárias. O poder doravante se concentra aí, até a Revolução de 1930, hegemonizado pela oligarquia. Com a revolução, existiu o aceleramento da transição para o modelo de substituição de importações, também nomeado de desenvolvimentismo ou de industrialização. Os conflitos persistentes pela disputa de poder, somados à resistência popular do período e ao contexto internacional, tiveram como desfecho, em 1937, o Estado Novo. O breve período democrático, que se inaugura em 1945, trouxe esperanças nas reformas de base, as quais foram frustradas, e o resultante dos conflitos estabelecidos foi a ditadura de 1964 (Paludo, 2001).

Esta última opção traça mais uma ruptura histórica e coloca o Brasil num caminho de intensificação da perda de autonomia, embora sempre relativa em um mundo globalizado, para indicar seus próprios rumos e avançar nos direitos. De acordo com a análise de Frigotto (1991), desde os anos 1930 dois eixos polarizaram a luta pela definição do capitalismo brasileiro: a fortificação do mercado interno, perspectiva nacionalista-desenvolvimentista, e o capitalismo associado, intensificação da subordinação ao capitalismo transnacional e corporativo. A partir de 1964, há uma clara opção pelo segundo eixo. Os partidários desta última opção 
defendiam que o processo de industrialização só seria possível com o capital internacional. Internamente, o governo deveria buscar a estabilidade econômica por meio da adoção de medidas monetaristas, para melhor adequar o Brasil aos padrões do comércio internacional. $\mathrm{O}$ nacionalismo inspirava-se nos princípios da Comissão Econômica para a América Latina (CEPAL) e rejeitava a abertura, sem restrições, da economia ao capital estrangeiro. A alternativa proposta era recorrer ao capital nacional para o desenvolvimento econômico autônomo do Brasil e a solução dos problemas sociais. O Estado deveria mobilizar o capital necessário.

Após a ditadura de 1964, resultante de lutas e conectado com o movimento internacional - que se movia no direcionamento europeu e dos Estados Unidos ao Estado de bem-estar social -, ocorreu o processo de democratização, com forte participação popular, que mais uma vez foi permeado por esperanças concretizadas na chamada Constituição Cidadã. Estamos no ano de 1988. Em 1989, há a primeira eleição direta para presidente do Brasil; o "Campo Democrático e Popular", que se constitui ao longo da história brasileira e se afirma no processo de lutas pela redemocratização, perde as eleições (Paludo, 2015). Esse é o início da caracterização do modelo neoliberal de desenvolvimento no Brasil. Iniciou-se no governo de Fernando Collor de Mello, na década de 1990, e se consolidou massivamente nos anos seguintes por Fernando Henrique Cardoso, no processo das privatizações e da reforma do Estado brasileiro.

Hoje, é possível observar que houve a continuidade dessa política, após a vitória de Luiz Inácio Lula da Silva, em 2002 e 2006, e Dilma Rousseff, em 2010. Ainda que se possa dizer que houve, nesses governos, a tentativa de implementação da "terceira via", também chamada de "neodesenvolvimentismo" - que contou com o apoio de parte da burguesia industrial e financeira (na questão da terra não existiram progressos significativos), com o estreitamento das relações entre público e privado, com as "então" chamadas políticas compensatórias, focadas na pobreza e nos extratos da classe média mais empobrecida, e com o quietismo da esquerda, que parecia assistir ao que ocorria - o processo de implementação do neoliberalismo seguiu seu curso (Antunes, 2004). Um balanço crítico dessa opção, mais perceptível e melhor delineada nesta década, mas que se constitui desde os anos 1980, é oferecido por Benjamim mediante os seguintes aspectos:

- a condição colonial é reatualizada, pois o Estado volta a dedicar-se, principalmente, a intermediar a imposição, à nação, de diretrizes externas;

- o mercado internacional volta a predominar como estimulador dos centros dinâmicos da nossa economia;

- a base produtiva se fragiliza e as vulnerabilidades externas aumentam dramaticamente;

- o núcleo moderno da economia deixa de fornecer mão-de-obra;

- cresce a apartação que separa os brasileiros entre si;

- o território se fragmenta segundo lógicas excludentes;

- a identidade cultural se degrada.

Pela primeira vez na história contemporânea, governo e elites se descomprometem explicitamente com a continuidade do processo industrializador - e com a própria ideia de desenvolvimento - que cimentou o acordo político social 
básico do Brasil neste século e conferiu relativa estabilidade a uma sociedade tão desigual. (Benjamim, 1998, p. 60)

A presidente Dilma Rousseff é reeleita em 2014 e, em 2016, há o encerramento do processo do seu impedimento. O que se caracteriza como um golpe de Estado, ainda que exista quem defenda que não o tenha sido.

A presidente legitimamente eleita foi derrubada por um processo político baseado em leituras elásticas da Constituição e artimanhas jurídicas de diversas matizes, que tentam mostrar como lícito o conluio do judiciário com um Parlamento em sua maior parte corrupto e uma mídia corporativa a serviço das elites financeiras. (Jinkings, 2016, p. 12)

De acordo com a autora, três aspectos são importantes na origem da crise:

1. o abandono das promessas de campanha da presidente, assumindo o Programa do Partido da Social Democracia Brasileira (PSDB);

2. o documento "Uma ponte para o futuro", que foi publicado em 29 de outubro de 2015, como lançamento oficial da proposta de um novo governo para o Brasil; ${ }^{2} \mathrm{e}$

3. o agravamento repentino do quadro econômico e uma recessão que foi planejada, o PIB foi derrubado e criou-se um cenário de muita vulnerabilidade.

O que se percebe é que, mais uma vez, no decorrer do conjunto dos governos petistas, houve a divisão da burguesia interna. Novamente vive-se, ainda que de forma atualizada, a disputa pela direção de desenvolvimento, de modo articulado e subordinado ao capital internacional. Boito Junior (2016) assinala as frentes dessa disputa da seguinte maneira: de um lado, o governo e aliados — inclusive setores representativos do capital (Federação das Indústrias do Estado de São Paulo - FIESP), que buscavam crescimento econômico com forte participação das empresas nacionais, distribuição de renda e melhoria de vida das classes populares e de estratos mais desfavorecidos da classe média, uma política cultural mais favorável à aceitação da diversidade e ao acesso à escolarização, e, externamente, deixam de ter um alinhamento passivo com os Estados Unidos, implementando uma política de estreitamento das relações com América Latina e Caribe, África e Ásia. De outro lado, os neoliberais e seus aliados — os representantes do capital, que representam a burguesia integrada ao capital internacional, industrial, financeiro e agrário.

Com o aprofundamento do cenário que originou a crise, cujos fatores estão acima elencados, o "neodesenvolvimentismo" perde o apoio dos setores do capital que o sustentavam, da classe média, nos estratos médio e alto (com manifestações de massa), mídia e judiciário. $\mathrm{O}$ desfecho do golpe foi - e tem sido - a implementação do neoliberalismo em seu estado "duro e puro".

2 O referido documento foi apresentado pelo Partido Democrático Brasileiro (PMDB). Ele apresenta um programa de governo, político e econômico que contou com o apoio do Movimento Pró-Impeachment e pelos que detém a hegemonia da imprensa brasileira. Nele estão contidos os lineamentos centrais da política atual 
Löwy faz uma distinção entre duas acepções do que se convencionou chamar de esquerda. Distinção essa que sintetiza o que ocorreu aqui no Brasil e em grande parte na América Latina. Há, segundo o autor, dois governos de esquerda:

As coalizões social-liberais, que rompem com os fundamentos do "Consenso de Washington", mas realizam várias medidas sociais progressistas. O princípio básico desse tipo de governo é fazer tudo o que é possível para melhorar a situação dos pobres, com a condição de não tocar nos privilégios dos ricos... O governo de esquerda ou centro-esquerda no Brasil (antes da crise atual), do Uruguai e do Chile são exemplos evidentes desse modelo.

Governos antioligárquicos, antineoliberais e anti-imperialistas, que colocam como horizonte histórico o socialismo do século XXI. A Venezuela, Bolívia e Equador pertencem a essa categoria.

Outros governos de esquerda, no Paraguai, na Nicarágua, em El Salvador e Argentina eram situados no meio do caminho ou a margem desses dois tipos. (Löwy, 2016, p. 62)

É assim que todas as reformas propostas pelo atual governo (Trabalhista, PEC dos gastos, da Previdência, Tributária, Política, com a da Educação), além de constituírem uma totalidade, têm como meta mudar o rumo do desenvolvimento brasileiro e, consequentemente, garantir o processo de acumulação do capital, mesmo que isso signifique um grande retrocesso, em termos de direitos e de padrões mínimos de sociabilidade humanos.

Essa desidentidade entre indivíduo e gênero humano - e as múltiplas formas de estranhamento que daí decorrem - se universaliza sobre a produção generalizada de mercadorias, apesar de esta oferecer, pela primeira vez, as possibilidades para a multilateralidade humana. Mas, ao invés do homem voltado para-si-mesmo-conscientemente-como-gênero, tem-se o seu contrário. Nas palavras de Agnes Heller: "ao mesmo tempo que o capitalismo produz necessidades 'múltiplas e ricas', provoca o empobrecimento do homem e converte o ser que trabalha em um ser isento de necessidades". Constata-se, pois, um processo de homogeneização e redução das necessidades do ser social que trabalha, que deve privar-se de todas as suas necessidades para poder satisfazer uma só, manter-se vivo. (Antunes, 1997, p. 116)

É com esse entendimento, a partir da perspectiva analisada, que devem ser entendidas, como já se disse, as reformas educativas propostas na atualidade brasileira, assim como o papel do nosso fazer como pesquisadores. É no interior desse processo mais amplo, acima analisado, que as reformas educacionais ganham sentido concreto, desvinculado de idealismos. É necessária a obtenção de consensos e, para isso, precisa-se formar mentalidades aderentes e adaptadas a essa nova perspectiva de desenvolvimento, que corresponde às exigências do novo padrão de acumulação do capital. Parte dessa "nova" consciência social é garantida pela mídia, notadamente a televisiva; e parte, bastante importante, cabe ao sistema educacional, notadamente ao público, que é onde estão os trabalhadores e seus filhos. $\mathrm{O}$ que 
se vive, de acordo com Iasi (2014), é a "adaptação da realidade" aos interesses do capital. Profundamente ideológicas, por exemplo, a mídia e a proposta da "escola sem partido" invertem, ocultam, naturalizam, justificam e apresentam o particular como se fosse universal. O contexto diz da urgência de reunificar, na análise da realidade, a economia, a política, a cultura e a educação.

Ainda que sejam constatadas resistências a esse processo, é possível verificar que são bastante desarticuladas e que não há aspectos indenitários que possibilitem a unidade na ação, por parte do campo do trabalho. De um lado, a aposta em 2018, o que significa continuar insistindo na mudança apenas por dentro do Estado e reforça o distanciamento dos trabalhadores mais empobrecidos e suas organizações; e, de outro, os que estão convencidos de que a luta massiva deveria acontecer desde já. De modo geral, não é difícil afirmar que há uma espécie de internalização desse novo/velho modo de vida proposto, o que evidencia a hegemonia do campo que está no poder, mesclado por uma espécie de perda da esperança e descrédito quanto às possibilidades emancipatórias sob o sistema do capital. Destaca-se ainda o papel da mídia no processo de legitimação, que consegue massificar a ideia de que o problema central é a corrupção dos políticos e do partido que estava no governo.

\section{CONCLUSÕES E DESAFIOS PARA A PESQUISA}

O Brasil acompanhou e acompanha a lógica do sociometabolismo do capital, ou seja, da "acumulação, concentração e centralização", já preconizada por Marx, apesar das teorias que postulam que se esteja vivendo em uma sociedade pós-industrial, de conhecimento, etc. Essa lógica é dada pelas elites externas, articuladas internamente e, ao longo da história brasileira, sempre foram de cima para baixo, no que diz respeito à política. $\mathrm{Na}$ atualidade, o desfecho da crise do capital e o seu novo padrão de acumulação desconstituem, e não instituem, direitos, de todas as ordens. Assim como, apesar das possibilidades abertas pelo grande avanço tecnológico, apontam para o retrocesso nas relações de trabalho, para um patamar inferior ao que se tinha conquistado, traduzido nos direitos trabalhistas.

O novo direcionamento do desenvolvimento, apoiado pelos Estados Unidos da América, está sendo imposto, internamente, pelas reformas, que são exigidas pelos organismos multilaterais, e conta com a mídia, com o judiciário, com a presidência (partidos) e seus adeptos e com a violência simbólica e física, literalmente. A corrupção desenfreada é mais um elemento forte desse novo direcionamento, assim como $\mathrm{o}$ assalto do público pelo privado nacional, internacional e por meio de parcerias entre ambos. Da mesma forma, nota-se o retorno às relações de superexploração da força de trabalho - inclusive infantil —, o alargamento das massas desempregadas e subempregadas, a violência e a xenofobia de todo o tipo que se constituem e são estimuladas (vide Bolsonaro). Esses elementos apresentam-se explicitamente a favor do capital, agrário, industrial e financeiro, de poucos, portanto.

É evidente, que o desejo e a prática de uma sociabilidade solidária e de uma educação como "prática da liberdade", ou emancipatória, chocam-se com esse direcionamento. Dele pode-se esperar, no que tange à educação, o aumento do analfabetismo e do analfabetismo funcional, além de uma formação estreita e limitada teoricamente, notadamente, para as classes populares. 
Diante desse contexto, elenco três desafios que considero centrais para os pesquisadores e para as pesquisas. $\mathrm{O}$ primeiro diz respeito à revisão do referencial teórico metodológico que sustenta o ofício de pesquisador, uma vez que não são mais possíveis análises que não considerem as relações entre parte e totalidade, assim como análises que não sejam sustentadas em uma epistemologia que explicite as contradições centrais, subjacentes aos fenômenos em estudo; o segundo é a necessidade de debruçarem-se sobre a teoria, revisitando conceitos e categorias centrais para a análise dos fenômenos; ${ }^{3}$ o terceiro é o de assumir a perspectiva da transformação radical da sociedade, com pesquisas articuladas no Brasil, na América Latina e em outros países, estreitando laços e articulações com estratos da classe trabalhadora, suas reivindicações - terra, teto, trabalho, moradia - e defesa intransigente dos demais direitos - denunciar condições de vida e xenofobias e, ao mesmo tempo, contribuir para a formulação das possibilidades. $O$ grande desafio para os pesquisadores é o de assumir a dimensão política do pensar e fazer pesquisa.

\section{REFERÊNCIAS}

Anderson, P. Balanço do neoliberalismo. In: Sader, E.; Gentili, P. (Org.). Pós-neoliberalismo: as políticas sociais e o Estado democrático. Rio de Janeiro: Paz e Terra, 1995. p. 9-23.

Antunes, R. Adeus ao trabalho? Ensaio sobre as metamorfoses e a centralidade do mundo do trabalho. 4. ed. São Paulo: Cortez; UNICAMP, 1997.

. A desertificação neoliberal no Brasil: Collor, FHC e Lula. Campinas: Autores Associados, 2004.

. Introdução: a substância da crise. In: MÉszáros, S. A crise estrutural do capital. Tradução de Francisco Raul Cornejo. 2. ed. São Paulo: Boitempo, 2011.

Boito Junior, A. Os atores e o enredo da crise política. O golpe que tem vergonha de ser chamado de golpe. In: Cleto, M.; Jinking, I. (Orgs.) Por que gritamos golpe? Para entender o impeachment e a crise política no Brasil. São Paulo: Boitempo, 2016. p. 23-29. Benjamim, C.; Alberti, J. A.; Sader, E.; Stédile, J. P.; Albino, J.; Camini, L.; Bassegio, L.; Greenhalgh, L. E.; Sampaio, P. A.; Gonçalves, R.; Araújo, T. B. A op̧̧ão brasileira. Rio de Janeiro: Contraponto, 1998.

Carvalho,J. M. Os bestializados. O Rio de Janeiro e a República que não foi. São Paulo: Companhia das Letras, 1997.

Coutinho, C. N. Notas sobre cidadania e modernidade. Revista Praia Vermelha, Rio de Janeiro: UFRJ, v. 1, n. 1, 1997.

Chaú, M. Cultura e democracia: o discurso competente e outras falas. 3. ed. São Paulo: Moderna, 1982.

3 Como exemplos podem ser citados: o Estado, sua diferenciação de governo e o papel que cumpre na sociedade de classes; políticas públicas e o papel que cumprem na sociedade capitalista; democracia; trabalho, sua importância para a produção da vida humana; relação trabalho, política, cultura e condições dignas de vida. 
Chauí, M. Conformismo e resistência: aspectos da cultura popular no Brasil. São Paulo: Brasiliense, 1986.

. A história no pensamento de Marx. In: Boron, A. A; Amadeo, J.; Gonzáles, S. (Orgs.).A teoria marxista hoje: problemas e perspectivas. 1. ed. Buenos Aires: CLACSO; São Paulo: Expressão Popular, 2007. p. 143-181.

DiAs, E. F. Reestruturação produtiva: forma atual da luta de classes. Revista Outubro. Disponível em: <http://www.revistaoutubro.com.br/edicoes/01/out01_03.pdf>.Acesso em: 10 fev. 2016.

Fernandes, F. Capitalismo dependente e classe social na América Latina. Apresentação de Ricardo Antunes. 4. ed. São Paulo: Global, 2009.

Freire, P. À Sombra desta mangueira. São Paulo: Olho d'Água, 1995.

Frigotto, G. O contexto sociopolítico brasileiro e a educação nas décadas de 70/90. Contexto Ẽ Educação, Ijuí, v. 6, n. 24, p. 46-57, out./dez. 1991.

. O enfoque da dialética materialista histórica na pesquisa educacional. In: FAzenda, I. Metodologia da pesquisa educacional.6. ed. São Paulo: Cortez, 2000. p. 69-90. Gramsci, A. Obras escolbidas. São Paulo: Martins Fontes, 1978.

. Os intelectuais e a organização da cultura. Tradução de Carlos Nelson Coutinho. 4. ed. Rio de Janeiro: Civilização Brasileira, 1982.

Harvey, D. O enigma do capital: e as crises do capitalismo. Tradução de João Alexandre Peshanski. São Paulo: Boitempo, 2011.

Ianni, O. A ideia de Brasil moderno. São Paulo: Brasiliense, 1996.

IAsi, M. O socialismo, o idiota e a ideologia. 2014. Disponível em: <https:// blogdaboitempo.com.br/2014/01/23/o-socialismo-o-idiota-e-a-ideologia/>. Acesso em: 10 ago. 2017.

Jinkings, I. O golpe que tem vergonha de ser chamado de golpe.In: CLETo, M.; Jinking, I. (Orgs.). Por que gritamos golpe? Para entender o impeachment e a crise política no Brasil. São Paulo: Boitempo, 2016. p. 11-13.

Löwy, M. Da tragédia à farsa: o golpe de 2016 no Brasil. O golpe que tem vergonha de ser chamado de golpe. In: Cleto, M.; Jinking, I. (Orgs.). Por que gritamos golpe? Para entender o impeachment e a crise política no Brasil. São Paulo: Boitempo, 2016. p. 61-67.

Manacorda, M. A. Marx e a pedagogia moderna. São Paulo: Cortez/Autores Associados, 1991.

Marx, K. O capital. Livro 1. v. 1. 19. ed. Rio de Janeiro: Civilização Brasileira, 2002. Popular, 2009.

. Para a questão judaica. Tradução de Barata-Moura. São Paulo: Expressão

Marx, K.; Engels, F. Manifesto do partido comunista. São Paulo: Expressão Popular, 2008. ;_______ ideologia alemã. 1. ed. São Paulo: Expressão Popular, 2009.

Mascaro, A. L. Estado e forma politica. São Paulo: Boitempo, 2013.

Paludo, C. Educação popular em busca de alternativas: uma leitura desde o Campo Democrático Popular. Porto Alegre: Tomo Editorial, 2001.

. Educação popular como resistência e emancipação humana. Caderno CEDES, v. 35, n. 96, p. 219-238, maio./ago. 2015. 
Paludo, C.; Vitoria, F. B. Contribuições do materialismo histórico-dialético para a investigação das políticas sociais. In: Cunha, C.; Sousa, J. V.; Silva, M. A. (Orgs.). O método dialético na pesquisa em educação. 1. ed. Campinas: Autores Associados, 2014. p. 99-130.

Petras, J. A deterioração econômica da Europa. Entrevista de Graziela Wolfart, Márcia Junges e Patricia Fachin. Tradução de Lucas Schlupp. Revista do Instituto Humanitas Unisinos, ano X, n. 330, 24 maio 2010. Disponível em: <http://www.ihuonline.unisinos. $\mathrm{br} /$ index.php?option $=$ com_content\&view $=$ article\&id $=3231 \&$ secao $=330>$. Acesso em: 12 fev. 2016.

Prado Júnior, C. Formação do Brasil contemporâneo. 22. ed. São Paulo: Brasiliense, 1992. Poulantzas, N. O Estado, o poder, o socialismo. 2. ed. Rio de Janeiro: Edições Graal, 1985. Ribeiro, D. O povo brasileiro: a formação e o sentido do Brasil. 2. ed. São Paulo: Companhia das Letras, 1997.

SoAres, L. T. R. Ajuste neoliberal e desajuste social na América Latina. Rio de Janeiro: UFRJ, 1998.

SALAZAR, G. Integración formal e segregación real: matriz histórica de la autoeducación popular. In: Martinic, S.; Horacio, W (Eds.) Profesionales en la acción. Una mirada crítica a la educación popular. Santiago, Chile: CIDE, 1990. p. 102-114.

SAlvador, E. Fundo público e políticas sociais na crise do capitalismo. Revista Serviço. Social e Sociedade, São Paulo, n. 104, p. 605-631, out./dez. 2010.

Thompson, E. P. A miséria da teoria ou um planetário de erros: crítica ao pensamento de Althusser. Tradução de Waltensir. Rio de Janeiro: Zahar Editores, 1981.

Trotski, L. Prefácio de junho de 1905 à edição russa dos discursos de Ferdinand Lassale. In: Löwy, M. A teoria do desenvolvimento desigual e combinado. Disponível em: <http:// www.afoiceeomartelo.com.br/posfsa/Autores/Lowy,\%20Michael/a\%20teoria\%20 do\%20desenvolvimento\%20desigual\%20e\%20combinado.pdf >. Acesso em: 10 jul. 2017. Triviños, A. N. S. Introdução à pesquisa em ciências sociais: a pesquisa qualitativa em educação. São Paulo: Atlas, 1987.

\section{SOBRE A AUTORA}

Conceição Paludo é doutora em educação pela Universidade Federal do Rio Grande do Sul (UFRGS). Professora da mesma instituição.

E-mail: c.paludo@terra.com.br

Recebido em 9 de novembro de 2017 Aprovado em 24 de maio de 2018 